\title{
Can CAPTURE be used to identify undiagnosed patients with mild-to-moderate COPD likely to benefit from treatment?
}

This article was published in the following Dove Press journal: International Journal of COPD

\author{
Nancy K Leidy,' Fernando J \\ Martinez, ${ }^{2}$ Karen G Malley, \\ David M Mannino, ${ }^{3}$ MeiLan \\ K Han, ${ }^{4}$ Elizabeth D Bacci, ${ }^{5}$ \\ Randall W Brown, ${ }^{6}$ Julia $\mathrm{F}$ \\ Houfek, ${ }^{7}$ Wassim W Labaki, ${ }^{4}$ \\ Barry J Make, ${ }^{8}$ Catherine A \\ Meldrum, ${ }^{4}$ Wilson Quezada, ${ }^{9}$ \\ Stephen Rennard, ${ }^{10}$ Byron \\ Thomashow, ${ }^{9}$ Barbara P Yawn" \\ 'Evidera, Patient-Centered Research, \\ Bethesda, MD, USA; ${ }^{2}$ Weill Cornell \\ Medicine, Joan \& Sanford Weill \\ Department of Medicine, New York, NY, \\ USA; ${ }^{3}$ University of Kentucky, Preventive \\ Medicine \& Environmental Health, \\ Lexington, KY, USA; ${ }^{4}$ University of Michigan, \\ Division of Pulmonary \& Critical Care \\ Medicine, Ann Arbor, MI, USA; ${ }^{5}$ Evidera, \\ Patient-Centered Research, Seattle,WA, \\ USA; ${ }^{6}$ University of Michigan, Department \\ of Health Behavior \& Health Education, \\ School of Public Health, Ann Arbor, MI, \\ USA; 'University of Nebraska Medical \\ Center College of Nursing, Omaha, NE, \\ USA; ${ }^{8}$ National Jewish Health, Department \\ of Medicine, Division of Pulmonary, Critical \\ Care \& Sleep Medicine, Denver, CO, USA; \\ ${ }^{9}$ Columbia University Medical Center, \\ Division of Pulmonary, Allergy, \& Critical \\ Care, New York, NY, USA; ${ }^{10}$ AstraZeneca, \\ IMED Biotech Unit, Cambridge, UK \& \\ University of Nebraska Medical Center, \\ Department of Medicine, Omaha, NE, USA; \\ "University of Minnesota, Department of \\ Family \& Community Health, Minneapolis, \\ MN \& COPD Foundation, Miami, FL, USA
}

Correspondence: Nancy K Leidy Evidera, 710I Wisconsin Avenue, Suite 1400, Bethesda, MD 208I4, USA Tel +I 3016647272 Fax + I 30I 6549864 Email nancy.leidy@evidera.com
Background: COPD Assessment in Primary Care To Identify Undiagnosed Respiratory Disease and Exacerbation Risk (CAPTURE ${ }^{\mathrm{TM}}$ ) uses five questions and peak expiratory flow (PEF) thresholds (males $\leq 350 \mathrm{~L} / \mathrm{min}$; females $\leq 250 \mathrm{~L} / \mathrm{min}$ ) to identify patients with a forced expiratory volume in 1 second $\left(\mathrm{FEV}_{1}\right)$ /forced vital capacity $(\mathrm{FVC})<0.70$ and $\mathrm{FEV}_{1}<60 \%$ predicted or exacerbation risk requiring further evaluation for COPD. This study tested CAPTURE's ability to identify symptomatic patients with mild-to-moderate $\mathrm{COPD}\left(\mathrm{FEV}_{1} 60 \%-80 \%\right.$ predicted) who may also benefit from diagnosis and treatment.

Methods: Data from the CAPTURE development study were used to test its sensitivity (SN) and specificity (SP) differentiating mild-to-moderate COPD $(n=73)$ from no COPD $(n=87)$. SN and SP for differentiating all COPD cases (mild to severe; $n=259$ ) from those without COPD $(n=87)$ were also estimated. The modified Medical Research Council (mMRC) dyspnea scale and COPD Assessment Test (CAT ${ }^{\mathrm{TM}}$ ) were used to evaluate symptoms and health status. Clinical Trial Registration: NCT01880177, https://ClinicalTrials.gov/ct2/show/NCT01880177?term=N CT01880177\&rank=1.

Results: Mean age (+SD): 61 (+10.5) years; 41\% male. COPD: $\mathrm{FEV}_{1} / \mathrm{FVC}=0.60(+0.1), \mathrm{FEV}_{1} \%$ predicted $=74 \%(+12.4)$. SN and SP for differentiating mild-to-moderate and non-COPD patients ( $\mathrm{n}=160$ ): Questionnaire: $83.6 \%, 67.8 \%$; PEF ( $\leq 450 \mathrm{~L} / \mathrm{min} ; \leq 350 \mathrm{~L} / \mathrm{min}$ ): 83.6\%, 66.7\%; CAPTURE (Questionnaire+PEF): 71.2\%, 83.9\%. COPD patients whose CAPTURE results suggested that diagnostic evaluation was warranted $(\mathrm{n}=52)$ were more likely to be symptomatic than patients whose results did not ( $\mathrm{n}=21)(\mathrm{mMRC}>2: 37 \%$ vs $5 \%, p<0.01$; CAT $>10: 86 \%$ vs $57 \%, p<0.01)$. CAPTURE differentiated COPD from no COPD ( $n=346$ ): SN: $88.0 \%$, SP: $83.9 \%$.

Conclusion: CAPTURE (450/350) may be useful for identifying symptomatic patients with mild-to-moderate airflow obstruction in need of diagnostic evaluation for COPD.

Keywords: COPD, case-finding, undiagnosed COPD, screening tool, peak expiratory flow

\section{Introduction}

COPD Assessment in Primary Care to Identify Undiagnosed Respiratory Disease and Exacerbation Risk (CAPTURE ${ }^{\mathrm{TM}}$ ) was developed to identify people with severe, high-risk undiagnosed COPD, defined as a forced expiratory volume in 1 second $\left(\mathrm{FEV}_{1}\right)<60 \%$ predicted or exacerbation risk, in primary care settings. ${ }^{1,2}$ This casefinding method uses five simple patient-completed questions and the selective use of peak expiratory flow (PEF) to uncover individuals most likely to benefit from diagnosis and treatment. ${ }^{1-8}$ The intent is to be as efficient as possible, using PEF selectively based on questionnaire score and reserving spirometry referrals to the subset of patients whose results warrant further diagnostic evaluation. ${ }^{1,3,4}$ 
Although this case-finding method was developed to identify undiagnosed patients with an $\mathrm{FEV}_{1} \%$ predicted $<60 \%$ or at risk of exacerbation, uncovering symptomatic patients with $\mathrm{FEV}_{1} \%$ predicted $>60 \%$ who might also benefit from treatment could be advantageous. This study explored the extent to which CAPTURE identifies these patients.

In its initial testing, CAPTURE was able to differentiate cases of COPD $\left(\mathrm{FEV}_{1} \%\right.$ predicted $<60 \%$ or exacerbation risk) from controls without COPD with a sensitivity (SN) of $89.7 \%$ and specificity (SP) of $93.1 \%(\mathrm{n}=273)$. When subjects with milder $\mathrm{COPD}$ ( $\mathrm{FEV}_{1} \%$ predicted $\geq 60 \%$ and no/low exacerbation risk) were included in the control group, testing the ability of CAPTURE to differentiate the more severe, high-risk patients from all others, SN was $89.7 \%$ and SP was $78.1 \%(\mathrm{n}=346) .{ }^{1}$ The change in SP indicated that CAPTURE was classifying some patients with milder airflow obstruction as cases, a finding interpreted as error because the intent was to find the more severe, high-risk patients. ${ }^{1}$ Upon further reflection, we questioned whether these "misclassified" cases may represent an additional group of patients who might also benefit from diagnosis and treatment. Although screening of asymptomatic individuals for undiagnosed COPD is not recommended, ${ }^{9}$ identifying symptomatic patients with mild-to-moderate airflow limitation could be advantageous, with treated individuals potentially realizing symptomatic, activity tolerance, and health-status benefits. ${ }^{10-14}$

\section{Methods}

\section{Design}

This was a secondary analysis of data from the prospective, cross-sectional, multisite, case-control study used to develop CAPTURE. ${ }^{1,15}$ Specific methods and procedures for the larger study are presented elsewhere. ${ }^{1}$ The study was approved by a central institutional review board (IRB) (Schulman Associates) and IRBs at each study site (Columbia University, National Jewish Health, Olmsted Medical Center, University of Kentucky, University of Michigan, and University of Nebraska Medical Center). Each patient provided written informed consent before initiating study procedures. Briefly, for questionnaire development, a pool of 44 candidate questions and criterion measures were completed by patients identified as cases $\left(\mathrm{n}=186 ; \mathrm{FEV}_{1}<60 \%\right.$ or $\geq 1$ exacerbation the previous 12 months) or controls ( $\mathrm{n}=160$; including patients with COPD and $\mathrm{FEV}_{1} \geq 60 \%$ predicted and no exacerbations the prior 12 months [ $\mathrm{n}=73]$ and those without COPD [n=87]). ${ }^{1}$ COPD was defined by physician diagnosis with prescribed pharmacologic maintenance therapy and $\mathrm{FEV}_{1} / \mathrm{FVC}<0.70$. COPD patients with an $\mathrm{FEV}_{1} \%$ predicted of $60 \%-80 \%$ were included in the control group to optimize the selection of items most sensitive to more severe, high-risk COPD during random forests analyses. The precision of the questionnaire alone, PEF alone, and CAPTURE (Questionnaire+PEF) for differentiating cases $(n=186)$ from non-COPD controls $\left(\mathrm{n}=87\right.$ ) was also tested. ${ }^{1}$

To address the purpose of the current study, analyses were performed on data from the original control group $(n=160)$, with cases defined by a diagnosis of COPD, $\mathrm{FEV}_{1} \geq 60 \%$ predicted, and no exacerbation the prior 12 months $(n=73)$ and those with no COPD serving as controls $(\mathrm{n}=87)$. The entire dataset ( $n=346$ ) was used to evaluate CAPTURE across the full range of COPD $(n=259)$, with patients without COPD $(n=87)$ serving as controls.

\section{Measures}

\section{The CAPTURE Questionnaire}

The CAPTURE Questionnaire (Figure 1) comprises five questions assessing the presence/absence of symptoms (breathing problems and tiring easily), risk exposures, and recent history of acute respiratory illnesses. Responses are summed to yield a score ranging from 0 (no to all 5 questions) to 6 (yes to all questions and $>2$ respiratory events during the past year). Scores $\geq 2$ indicate that further diagnostic assessment for COPD is warranted. In its initial testing, scores $\geq 2$ showed an SN of $95.7 \%$ and an SP of $44.4 \%$ for differentiating COPD cases $\left(\mathrm{FEV}_{1} \%\right.$ predicted $<60 \%$ or exacerbation risk) from controls (mild/moderate no risk COPD or no COPD) and an SN of $95.7 \%$ and an SP of $67.8 \%$ for differentiating cases from those without COPD. ${ }^{1}$

\section{PEF}

PEF is used to increase the precision of case identification. In the development/validation study, research staff supervised PEF administration (Vitalograph ${ }^{\circledR}$ AsmaPlan ${ }^{\circledR}$ mechanical PEF meter; Vitalograph Ltd, Buckingham, UK) during the clinic visit; each subject performed three maneuvers with the highest value $(\mathrm{L} / \mathrm{min})$ used for analyses. Sex-specific thresholds were identified to facilitate rapid interpretation in clinical practice prior to referral for diagnostic spirometry: males $<350 \mathrm{~L}$ per minute $(\mathrm{L} / \mathrm{min})$ and females $<250 \mathrm{~L} / \mathrm{min} .{ }^{1}$

\section{CAPTURE (Questionnaire+PEF)}

Questionnaire scores are used to select the best subset of patients for PEF testing. Those scoring 0 or 1 on the questionnaire are unlikely to have COPD and can proceed with the remainder of their clinic visit. Those scoring 5 or 6 (yes to all items and $\geq 1$ respiratory events the past year) may have 


\section{CAPTURE* TM}

For each question, place an $\mathrm{X}$ in the box with the answer that is best for you.

There are no right or wrong answers, only answers which are right for you.

\begin{tabular}{|c|c|c|c|}
\hline Please answer each question & No & & Yes \\
\hline $\begin{array}{l}\text { 1. Have you ever lived or worked in a place with dirty or } \\
\text { polluted air, smoke, second-hand smoke, or dust? }\end{array}$ & $\square$ & & $\square$ \\
\hline $\begin{array}{l}\text { 2. Does your breathing change with seasons, weather, or air } \\
\text { quality? }\end{array}$ & $\square$ & & $\square$ \\
\hline $\begin{array}{l}\text { 3. Does your breathing make it difficult to do things such as carry } \\
\text { heavy loads, shovel dirt or snow, jog, play tennis, or swim? }\end{array}$ & $\square$ & & $\square$ \\
\hline \multirow[t]{2}{*}{ 4. Compared to others of your age, do you tire easily? } & $\square$ & & $\square$ \\
\hline & 0 & 1 & $\begin{array}{l}2 \text { or } \\
\text { more }\end{array}$ \\
\hline $\begin{array}{l}\text { 5. In the past } 12 \text { months, how many times did you miss work, } \\
\text { school, or other activities due to a cold, bronchitis, or pneumonia? }\end{array}$ & $\square$ & & 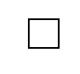 \\
\hline
\end{tabular}

* $\underline{\mathbf{C} O P D}$ Assessment in Primary Care to identify Undiagnosed Respiratory Disease \& Exacerbation Risk

Figure I The CAPTURE ${ }^{\mathrm{TM}}$ (COPD assessment in primary care to identify undiagnosed respiratory disease and exacerbation risk) questionnaire.

Notes: Scoring: No =0; Yes =I; Item 5: 0, I, 2. Scores are summed. (c) Cornell University, University of Kentucky Research Foundation, and Evidera, Inc. All rights reserved.

undiagnosed disease and can be referred directly to spirometry. Patients scoring 2-4 are clinically equivocal, with PEF values relative to thresholds used to determine next steps (spirometry and no spirometry). In the development study, this two-step process, using the 350/250 L/min thresholds, improved SN and SP over the questionnaire alone for differentiating cases and controls $(89.7 \%$ and $78.1 \%)$ and cases and no-COPD controls (89.7\% and 93.1\%), with the added advantage of eliminating the need for PEF assessments in all patients. ${ }^{1}$

\section{Modified British Medical Research Council dyspnea scale (mMRC) and COPD Assessment Test (CAT TM)} The mMRC ${ }^{16,17}$ and $\mathrm{CAT}^{\mathrm{TM} 18,19}$ were used to assess patientreported dyspnea and COPD-related health status, respectively. The mMRC is a 5-point (0-4) scale with higher ratings reflecting more severe breathlessness. CAT scores range from 0 to 40 with higher scores indicating poorer COPD health status. Patient-level scores $<10$ are interpreted as low-impact COPD, with continued health maintenance interventions advised, including smoking cessation, vaccination, and exercise. Scores 10-20 are considered moderate-impact COPD with potential for improvement with treatment, for example, maintenance therapies, reduction in aggravating factors, exacerbation prevention, and/or rehabilitation. ${ }^{20} \mathrm{mMRC}$ $>2$ and CAT scores $>10$ are used to categorize patients as "more symptomatic" under the Global Initiative for Chronic Obstructive Lung Disease (GOLD) guidelines. ${ }^{21}$

\section{Spirometry}

Pre-bronchodilator spirometry $\left(\mathrm{FEV}_{1}, \mathrm{FEV}_{1} \%\right.$ predicted, and $\mathrm{FEV}_{1}$ /forced vital capacity [FVC]) was performed if spirometry results from the past 5 years were not available. $\mathrm{FEV}_{1} / \mathrm{FVC}<0.70$ and $\mathrm{FEV}_{1}<80 \%$ predicted were considered diagnostic of COPD. All COPD cases met COPD Foundation Guide spirometry grade 1 requirements ( $\mathrm{FEV}_{1}$ $\geq 60 \%$; $<80 \%$ predicted) ${ }^{7}$

\section{Analyses}

Group differences in sample characteristics were tested using parametric (normally distributed continuous variables) and nonparametric (categorical and non-normal continuous variables) statistics. PEF values were also compared using analysis of variance, with factors for group, sex, smoking, age, and group-by-sex interaction.

The precision of the questionnaire, PEF (350/250), and CAPTURE (Questionnaire+PEF [350/250]) for differentiating patients with and without COPD in this sample was estimated using SN, SP, overall misclassification error estimates, receiver operator characteristic curves, and area under the curve.

The SN, SP, and error for PEF alone were examined in $25 \mathrm{~mL}$ increments stratified by sex to determine if higher thresholds more accurately differentiated these cases of COPD from those without COPD, with consideration given to threshold values that would be easy to recall and apply in clinical settings. 
The best thresholds were then tested with the questionnaire to determine if new thresholds for males and females would enhance the precision of CAPTURE in this population.

The extent to which CAPTURE was identifying COPD patients with dyspnea (mMRC levels $>2$ ) and/or poor health status (CAT scores $>10$ ) was tested using Chi-square $\left(\chi^{2}\right)$ or Fisher's exact (cell $\mathrm{n}<5$ ) statistics and performed using the 350/250 and the higher PEF thresholds.

Finally, SN, SP, and error for differentiating the full range of COPD $(n=259)$ from no COPD $(n=87)$ were assessed for the questionnaire alone, PEF alone, and CAPTURE using the 350/250 and higher PEF thresholds.

\section{Results}

\section{Sample}

Demographic and clinical characteristics of the analytical sample are shown in Tables 1 and 2. Subjects without COPD were younger and more likely to be female, employed, and have a higher educational level than the COPD group.

Of the 73 patients with milder COPD, 23 (31.5\%) were GOLD airflow limitation category 1 (mild) and 50 (68.5\%) were GOLD 2 (moderate). ${ }^{21}$ COPD patients had significantly poorer lung function, higher mMRC and CAT scores, and

Table I Demographic characteristics by group ${ }^{a}$

\begin{tabular}{|c|c|c|c|}
\hline \multirow[t]{2}{*}{ Characteristic } & \multicolumn{2}{|l|}{$n=160$} & \multirow[t]{2}{*}{$p$-value } \\
\hline & $\begin{array}{l}\text { COPD }^{b} \\
(n=73)\end{array}$ & $\begin{array}{l}\text { No COPD } \\
(n=87)\end{array}$ & \\
\hline \multicolumn{4}{|l|}{ Age (years) } \\
\hline Mean (SD) & $65.2(9.1)$ & $58.1(10.5)$ & $<0.000$ I \\
\hline Range & $49-85$ & $40-88$ & \\
\hline Sex, n (\%) male & $40(55)$ & $26(30)$ & 0.0014 \\
\hline \multicolumn{4}{|l|}{ Ethnic background, n (\%) } \\
\hline Not Hispanic or Latino & $68(99)$ & $84(99)$ & 1.000 \\
\hline \multicolumn{4}{|l|}{ Racial background, n (\%) ${ }^{d}$} \\
\hline White & $66(90)$ & $73(84)$ & $0.2250^{\mathrm{a}}$ \\
\hline Non-white & $7(10)$ & $14(16)$ & \\
\hline \multicolumn{4}{|l|}{ Employment, n (\%) } \\
\hline Employed (full- or part-time) & $15(2 \mid)$ & $55(63)$ & $<0.000$ I \\
\hline Not employed & $58(79)$ & $32(37)$ & \\
\hline Retired & $37(5 I)$ & $22(25)$ & \\
\hline Disabled & $18(25)$ & $3(3)$ & \\
\hline Others ${ }^{\mathrm{e}}$ & $3(4)$ & $7(8)$ & \\
\hline Education status, n (\%) & & & 0.0006 \\
\hline High school or less & $36(49)$ & $18(2 \mid)$ & \\
\hline Some college, vocational training & $14(19)$ & $22(25)$ & \\
\hline College degree or more & $23(32)$ & $47(54)$ & \\
\hline
\end{tabular}

Notes: ${ }^{a}$ English-speaking with informed consent and spirometry. ${ }^{\mathrm{b}} \mathrm{COPD}, \mathrm{FEV}, 60 \%-$ $80 \%$ predicted, and no history of exacerbations $>12$ months. 'No known diagnosis or treatment for COPD and $\mathrm{FEV}, / F V C \geq 0.70$. ${ }^{d}$ Subject self-identified; American Indian or Alaskan Native (I,I), Asian (0,I), Black or African American (II, 5), and others $(2,0)$. ${ }^{e}$ Others: homemaker, unemployed, and not specified.

Abbreviation: $\mathrm{FEV}_{1}$, forced expiratory volume in I second.
Table 2 Clinical characteristics by group ${ }^{a}$

\begin{tabular}{|c|c|c|c|}
\hline \multirow[t]{2}{*}{ Characteristic } & \multicolumn{2}{|l|}{$n=160$} & \multirow[t]{2}{*}{$p$-value } \\
\hline & $\begin{array}{l}\text { COPD }^{b} \\
(n=73)\end{array}$ & $\begin{array}{l}\text { No COPD } \\
(n=87)\end{array}$ & \\
\hline \multicolumn{3}{|l|}{ Smoking history, n (\%) } & $<0.0001$ \\
\hline Never or $<100$ cigarettes & $2(3)$ & $51(59)$ & \\
\hline Former & $48(66)$ & $28(32)$ & \\
\hline Current & $23(32)$ & $8(9)$ & \\
\hline \multicolumn{4}{|l|}{ Spirometry } \\
\hline $\mathrm{FEV}_{1}$, median & 2.0 & 2.6 & $<0.0001$ \\
\hline Mean (SD) & $2.1(0.6)$ & $2.6(0.7)$ & \\
\hline $\mathrm{FEV}_{1} \%$ predicted & 70.0 & 93.0 & $<0.000$ I \\
\hline Mean (SD) & $74.0(12.4)$ & $89.7(14.6)$ & \\
\hline $\mathrm{FEV}_{1} / \mathrm{FVC}$, mean (SD) & $0.6(0.1)$ & $0.8(0.1)$ & $<0.0001$ \\
\hline \multirow[t]{2}{*}{ Peak flow (PEF) } & 316.1 & 403.5 & $<0.0001$ \\
\hline & $(102.86)$ & $(109.00)$ & \\
\hline \multicolumn{4}{|c|}{ mMRC dyspnea scale (0-4 scale) } \\
\hline Median & 2 & I & $<0.0001$ \\
\hline Mode (n, \%) & I $(34 ; 46)$ & $0(7 I ; 82)$ & \\
\hline $\mathrm{mMRC}>2$ & $20(28)$ & $5(6)$ & \\
\hline \multicolumn{4}{|l|}{ CAT $^{\mathrm{TM}}(0-40$ scale $)$} \\
\hline Median & 15.0 & 4.0 & $<0.0001$ \\
\hline Mean (SD) & $15.6(8.0)$ & $5.5(5.4)$ & \\
\hline CAT $>10, n(\%)$ & $57(78)$ & $13(15)$ & $<0.0001$ \\
\hline $\begin{array}{l}m M R C>2 \text { or } C A T>10 \\
n(\%)\end{array}$ & $57(78)$ & $15(17)$ & $<0.000$ I \\
\hline $\begin{array}{l}\mathrm{mMRC}>2 \text { and } C A T>10, \\
\mathrm{n}(\%)\end{array}$ & $20(28)$ & $3(3)$ & $<0.0001$ \\
\hline \multicolumn{3}{|l|}{$\mathrm{n}(\%)$ yes } & 0.0010 \\
\hline \multicolumn{4}{|l|}{ days, $\mathrm{n}(\%)$} \\
\hline $\begin{array}{l}\text { Sit, lie down, walk around } \\
\text { home }\end{array}$ & $38(52)$ & $32(37)$ & \\
\hline Very active or exercise & $35(48)$ & $55(63)$ & \\
\hline
\end{tabular}

Notes: anglish-speaking subjects with informed consent and spirometry. ${ }^{\mathrm{b}} \mathrm{COPD}$, FEV , 60\%-80\% predicted, and no history of exacerbations $>12$ months. 'No known diagnosis or treatment for COPD and $F E V_{1} / F V C \geq 0.70$.

Abbreviations: CAT, COPD Assessment Test; $\mathrm{FEV}_{1}$, forced expiratory volume in I second; FVC, forced vital capacity; mMRC, modified Medical Research Council dyspnea scale; PEF, peak expiratory flow.

were more likely to have a smoking history and one or more comorbid conditions than those with no COPD. PEF rates were significantly lower in the COPD group, tested alone and controlling for age $(p<0.001)$, sex $(p<0.0001)$, and smoking status $(p<0.01)$ (LS means [95\% CI]: COPD [n=73]: 324.3 [301.6; 346.9]; no COPD [n=87]: 403.1 [381.2, 425.1]; $\mathrm{F}=27.78 ; p<0.001)$.

\section{CAPTURE performance}

Performance properties of the questionnaire, PEF, and questionnaire+PEF for these milder COPD cases versus no COPD are shown in Table $3 \mathrm{~A}$ and Figure 2A. To assist with interpretation, results for the more severe high-risk COPD cases $\left(\mathrm{FEV}_{1}<60 \%\right.$ or risk of exacerbation) versus no COPD controls from the original development study ${ }^{1}$ are provided 
Table 3 Performance properties for questionnaire, PEF, and CAPTURE for differentiating COPD from no COPD

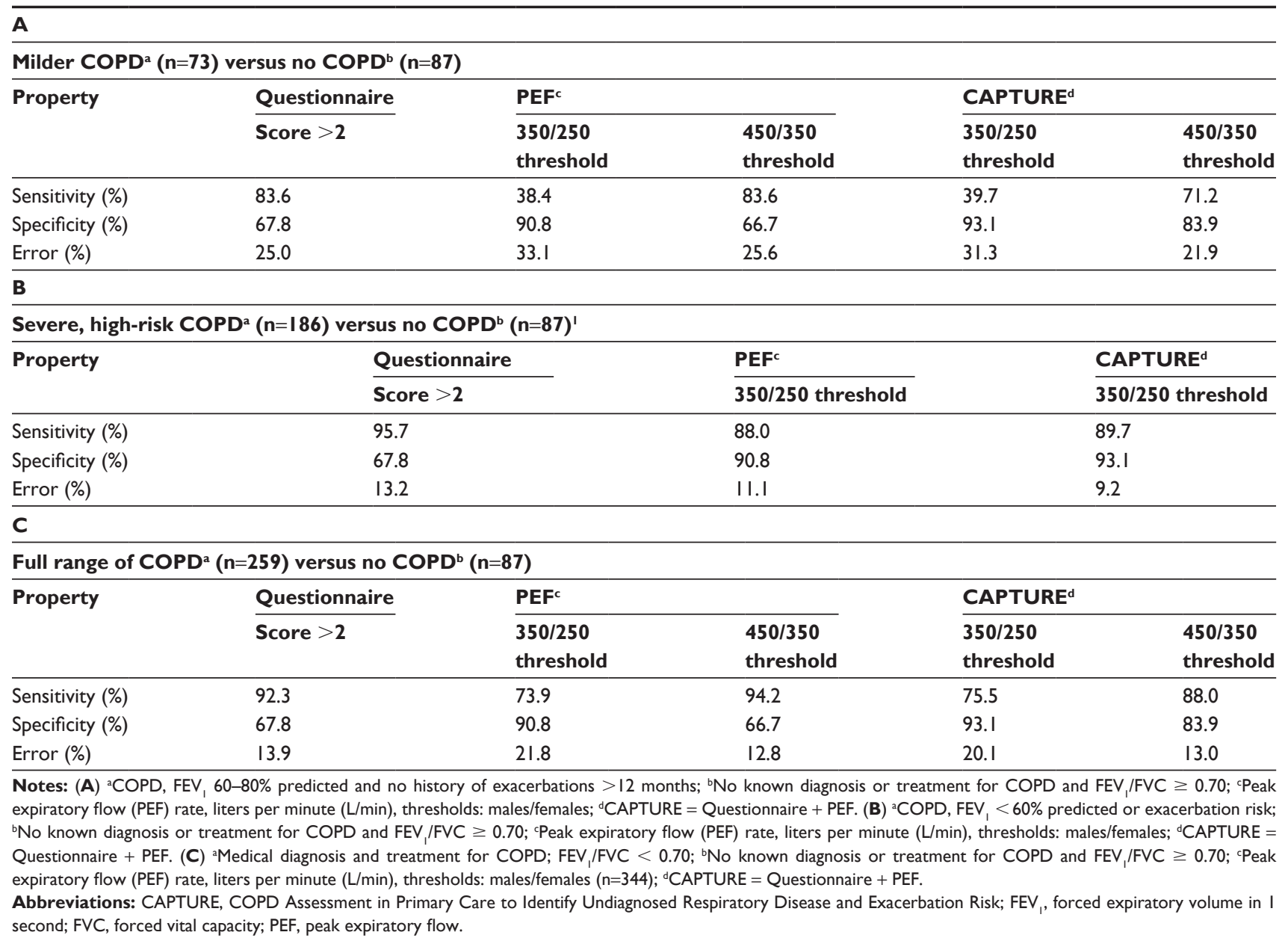

in Table 3B and Figure 2B. Results for all COPD versus no COPD are shown in Table 3C and Figure 2C. SN analyses for smoking status are included in Tables $\mathrm{S} 1-\mathrm{S} 3$, with results suggesting that this was not a confounding factor.

\section{Questionnaire alone}

Most COPD patients $(61 / 73 ; 83.6 \%)$ scored $\geq 2$ on the questionnaire, the threshold for further evaluation of COPD. The questionnaire was less sensitive differentiating milder COPD from no COPD $(83.6 \%$, Table $3 \mathrm{~A})$, relative to its use detecting more severe cases of COPD (95.7\%, Table 3B).

\section{PEF alone}

PEF (350/250 threshold) was less sensitive differentiating milder COPD patients from those without COPD (38.4\%, Table $3 \mathrm{~A}$ ) relative to its performance with more severe cases of COPD (88.0\%, Table 3B). Precision estimates for $\mathrm{PEF}$ at $25 \mathrm{~L} / \mathrm{min}$ increments are shown in Table S4A and B. Increasing the threshold by $100 \mathrm{~L} / \mathrm{min}$ (to $450 / 350$ for males/ females) improved the SN of PEF from $38.4 \%$ to $83.6 \%$, with some sacrifice in SP, from $90.8 \%$ to $66.7 \%$ (Table $3 \mathrm{~A}$ ).

\section{CAPTURE (Questionnaire+PEF)}

As one might expect given its purpose and development methods, CAPTURE (PEF 350/250) had substantially lower SN for detecting patients with milder airflow obstruction $(39.7 \%$, Table 3A) compared to the detection of patients with more severe, high-risk COPD (89.7\%, Table 3B). Using CAPTURE (PEF 450/350) improved the SN from 39.7\% to $71.2 \%$, with some sacrifice in SP, from $93.1 \%$ to $83.9 \%$ (Table $3 \mathrm{~A}$ ).

\section{Dyspnea and health status}

Most of the milder COPD patients scoring $\geq 2$ on the questionnaire reported either dyspnea $(\mathrm{mMRC} \geq 2 ; \mathrm{n}=50 / 60$; $83.3 \%$ ) or health status impairment (CAT $\geq 10 / 60 ; n=54 / 60$; $88.5 \%$ ). For patients with questionnaire scores $<2$, most $(9 / 12 ; 75 \%)$ had an mMRC $<2$ (mMRC missing for one subject) or CAT $<10(9 / 12,75 \%)$.

COPD patients whose CAPTURE (PEF 350/250) indicated the need for further diagnostic evaluation $(n=29)$ were more likely to report dyspnea (mMRC scores $\geq 2, p<0.05$ ) than those who did not $(n=44)$. There was no difference in health status $(\mathrm{CAT} \geq 10)$ between the two groups (Table S5). 
A

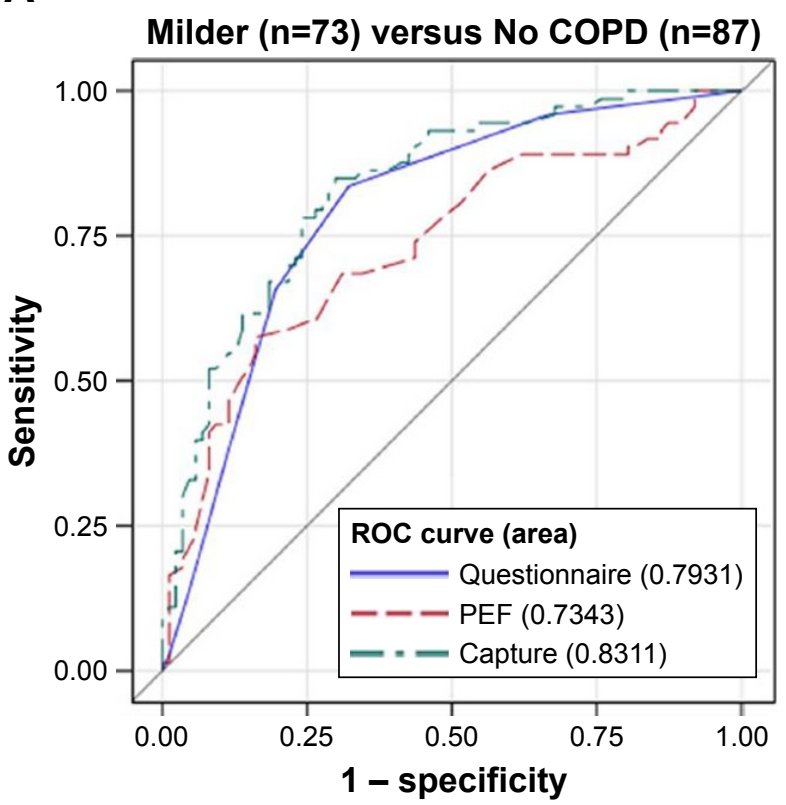

B Severe, High-Risk COPD $(n=186)$ vs No COPD $(n=87)$

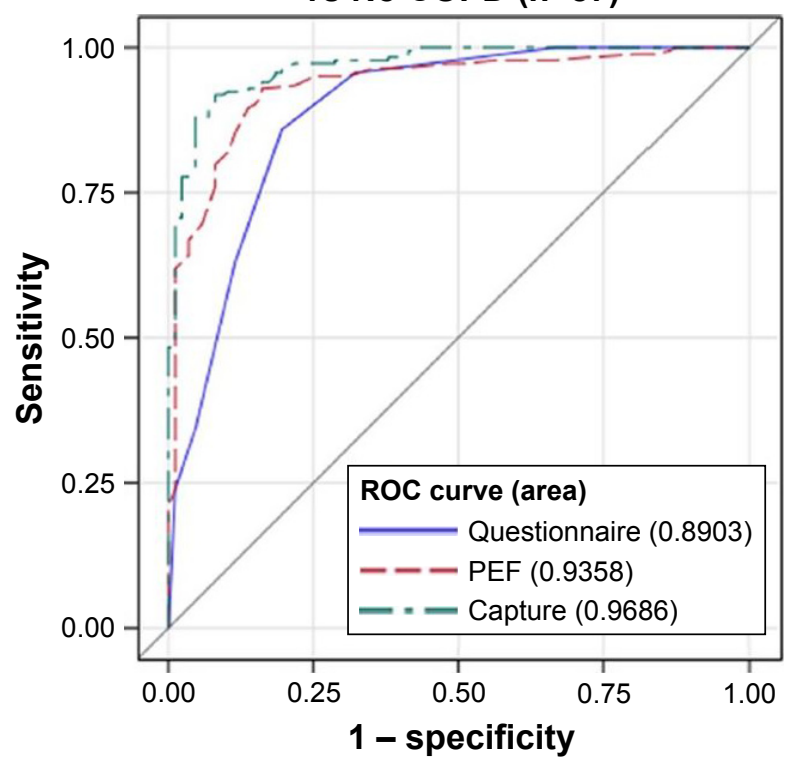

C All COPD $(n=259)$ versus No COPD $(n=87)$

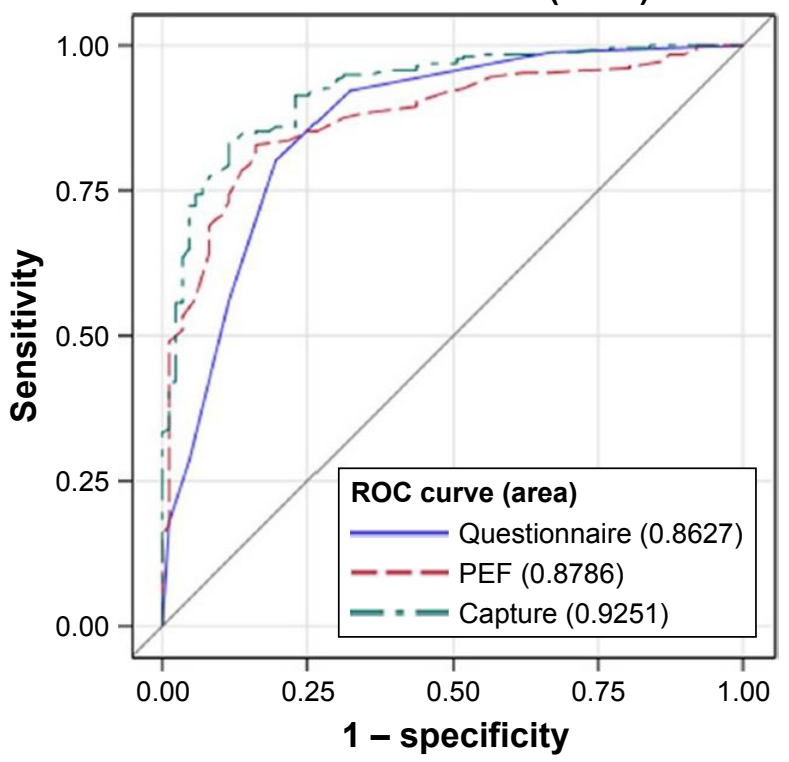

Figure $2 \mathrm{ROC}$ and $\mathrm{AUC}$ by group.

Notes: $(A)$ milder $^{a}(n=73)$ versus No $\operatorname{COPD}^{b}(n=87)$; (B) severe, high-risk COPD ${ }^{c}(n=186)$ versus no COPD $(n=87)$; $($ C) all COPD $(n=259)$ versus no COPD $(n=87)$. ${ }^{\mathrm{a} C O P D}, \mathrm{FEV}, 60 \%-80 \%$ predicted and no history of exacerbations $>12$ months. ${ }^{b}$ No known diagnosis or treatment for $\mathrm{COPD}$ and $\mathrm{FEV} / \mathrm{FVC} \geq 0.70$. ${ }^{\mathrm{C}} \mathrm{FEV},<60 \%$ or exacerbation risk. ${ }^{d} \mathrm{No}$ known diagnosis or treatment for COPD and $\mathrm{FEV}_{1} / \mathrm{FVC} \geq 0.70$.' eMedical diagnosis and treatment for COPD; FEV $/ \mathrm{FVC}<0.70$. ${ }^{\mathrm{N}} \mathrm{No}$ known diagnosis or treatment for COPD and $\mathrm{FEV}, / F V C \geq 0.70$.

Abbreviations: AUC, area under the curve; CAPTURETM, COPD Assessment in Primary Care to Identify Undiagnosed Respiratory Disease and Exacerbation Risk; $\mathrm{FEV}_{\mathrm{I}}$, forced expiratory volume in I second; FVC, forced vital capacity; PEF, peak expiratory flow; ROC, receiver operating characteristics.

Using the higher PEF threshold, COPD patients whose CAPTURE (PEF 450/350) suggested further evaluation $(\mathrm{n}=52)$ were more likely to be symptomatic $(\mathrm{mMRC} \geq 2$ and CAT $\geq 10, p<0.01)$ than patients whose scores suggested that no further assessment was warranted $(\mathrm{n}=21)$ (Table S3).

\section{Using CAPTURE to detect a full range of COPD, mild to severe}

As expected, using CAPTURE (PEF 350/250) to differentiate all patients with COPD from those without COPD alters the precision of the case-finding approach relative to its original purpose, reducing SN $(89.7 \%-75.5 \%)$ and 
increasing error $(9.2 \%-20.1 \%)$. Increasing the PEF threshold improves SN from $75.5 \%$ to $88.0 \%$ and reduces error $(20.1 \%-13.0 \%)$, with some sacrifice in SP (declines from $93.1 \%$ to $83.9 \%$ ).

\section{Discussion}

CAPTURE was designed to help primary care health professionals efficiently identify severe, high-risk undiagnosed cases of COPD in greatest need of diagnosis and treatment. Many patients with $\mathrm{FEV}_{1}>60 \%$ are symptomatic, however, and may also benefit from treatment. ${ }^{10,11,13,14}$ The results of the analyses presented here suggest that CAPTURE can identify these milder patients with reasonable SN and SP when PEF thresholds of 450/350 are used. Although more patients would be referred for diagnostic spirometric testing, including those without COPD, a substantial portion of those ultimately diagnosed with COPD are likely to have dyspnea or health status impairment that may be ameliorated with treatment.

Given the performance properties of PEF in the current analyses and previous study, one might be tempted to use PEF thresholds alone to identify patients in need of spirometry. However, organizing PEF supplies and performing three coached maneuvers with all patients in primary care settings, in addition to other clinic visit assessments, could be challenging. Furthermore, results of PEF provide preliminary information on airflow obstruction only, with no insight into exposure, symptoms, or exacerbation risk prior to referral for diagnostic testing. CAPTURE was designed to balance efficiency and precision, with the carefully designed questionnaire used as an initial screen and PEF administered to a subset of patients to yield fewer false positives and reduce screening costs. The PEF thresholds enable efficient interpretation, with empirically tested quick-recall values (male/ female, moderate to severe: $350 / 250$; mild to moderate: 450/350), although clinicians can also use the observed value and clinical judgment to determine the need for further assessment and testing.

Given the relatively high CAT scores in patients with questionnaire scores $\geq 2$, one might also ask if the CAT could be used for case finding. The CAT was developed to facilitate communication between COPD patients and clinicians, ${ }^{18}$ covering eight common manifestations of COPD and scores used to guide treatment. It was neither intended for use in patients without COPD nor as a screening tool. Following diagnosis, the CAT can be used to guide treatment and monitor outcomes. ${ }^{22}$
Several limitations of this study should be noted. First, this was an analysis of data from a subset of subjects participating in the CAPTURE development study, rather than a large prospective, population-based case-finding study. Results should be considered exploratory. Second, the COPD and no COPD groups differed on several sample characteristics. Some of these differences typify COPD and were expected; however, differences in demographics (particularly age, sex, and education) and smoking history could have affected the findings. Although there is no reason to believe that demographic differences altered patient responses to study measures, this must be recognized as a limitation with further study warranted. SN analyses in former smokers suggested that results were robust to smoking history. Third, spirometry values were measured without bronchodilator administration with the standard $\mathrm{FEV}_{1} /$ FVC diagnostic threshold of $<0.70$. Although other diagnostic indicators were also used for group assignment (medical diagnosis and treatment), the 0.70 threshold can result in an overestimation of older subjects with airflow limitation. Once again, further research is needed. Fourth, although CAPTURE has been tested and performs well identifying more severe, high-risk cases of COPD in Spanish-speaking patients, ${ }^{2}$ sample size precluded testing its performance in milder symptomatic COPD. Finally, CAPTURE is a tool to identify patients requiring further evaluation for COPD; it was not intended to diagnose or evaluate treatment and may detect problems other than COPD that warrant evaluation. It was also not intended for use as an outcome measure, with the CAT best suited to that purpose following diagnosis.

\section{Conclusion}

Results of these analyses together with those from the original validation study suggest that CAPTURE can be used to identify symptomatic patients likely to have airflow limitation and in need of further clinical evaluation for possible COPD. Based on the patient's score on this questionnaire, clinicians can apply the $350 / 250$ or $450 / 350$ PEF thresholds as they determine the need for diagnostic spirometry. Further testing in a large prospective study of this case-finding approach and its effect on diagnosis, treatment, and patient-centered outcomes are warranted.

\section{Acknowledgments}

The authors thank the subjects and High-Risk-COPD Screening Study Group for participation in the primary study. Also, thanks are due to Sonja Stringer for her organizational contributions throughout the project and Amara Tiebout for 
her assistance with manuscript formatting. Funding for this work was provided by the National Heart, Lung, and Blood Institute NHLBI: R01 HL114055. A portion of Dr Make's efforts was also supported by NHLBI: R01 HL089856 and R01 HL089897. As noted in the paper, this was a secondary analysis of data collected during the prospective, cross-sectional, multisite, case-control study used to develop CAPTURE. Methods and results of the primary paper were published in the American Journal of Respiratory and Critical Care Medicine (see the study by Martinez et al).

\section{Disclosure}

Nancy K Leidy, PhD and Elizabeth D Bacci, PhD are employees of Evidera, a health care research firm that provides consulting and other research services to pharmaceutical, device, government, and nongovernment organizations. In this salaried position, they work with various companies and receive no direct payment or honoraria from these companies for services rendered. Karen G Malley, BA is an hourly employee of Evidera and a salaried employee of Malley Research Programming, Inc. In the latter capacity, she provides custom computer programming services to clinical research organizations. Fernando J Martinez, MD, MS has participated in Steering Committee in COPD or IPF sponsored by Bayer, Centocor, Forest, Gilead, Janssen, GSK, Nycomed/Takeda, and Promedior. He has participated in advisory boards for COPD or IPF for Actelion, Amgen, Astra Zeneca, Boehringer Ingelheim, Carden Jennings, CSA Medical, Ikaria, Forest, Genentech, GSK, Janssens, Merck, Pearl, Nycomed/Takeda, Pfizer, Roche, Sudler \& Hennessey, Veracyte, and Vertex. He has prepared or presented continuing medical presentations in COPD or IPF for the American College of Chest Physicians, the American Thoracic Society, CME Incite, Center for Health Care Education, Inova Health Systems, MedScape, Miller Medical, National Association for Continuing Education, Paradigm, Peer Voice, Projects in Knowledge, Spectrum Health System, St John's Hospital, St Mary's Hospital, University of Illinois Chicago, University of Texas Southwestern, University of Virginia, UpToDate, and Wayne State University. Dr Martinez has participated in data safety monitoring committees sponsored by GSK and Stromedix. He has aided with FDA presentations sponsored by Boehringer Ingelheim, GSK, and Ikaria. He has spoken on COPD for Bayer, Forest, GSK, and Nycomed/ Takeda. He has participated in advisory teleconferences sponsored by the American Institute for Research, Axon, Grey Healthcare, Johnson and Johnson, and Merion. He has received book royalties from Informa. David Mannino, MD has received honoraria/consulting fees and served on speaker bureaus for GlaxoSmithKline plc, Novartis Pharmaceuticals, Pfizer Inc., Boehringer-Ingelheim, AstraZeneca PLC, Forest Laboratories Inc., Merck, Amgen, and Sunovion. Furthermore, he has received royalties from UptoDate, is on the Board of Directors of the COPD Foundation, and has been compensated as a medical expert in legal cases. MeiLan $\mathrm{K}$ Han, MD, MS has consulted for GSK, Boehringer-Ingelheim, AstraZeneca, Sunovion, and Novartis. Randall W Brown, MD MPH has served on the Board of Directors for the Allergy and Asthma Network and the National Asthma Education Certification Board. Dr Brown served on medical advisory boards for the Allergy and Asthma Foundation of America, AstraZeneca, Meda, Spirosure, Teva, and Thermo Fisher. Dr Brown received honoraria/consulting fees and served on speaker bureaus for tAstraZeneca, Meda, and Teva. Dr Brown has delivered continuing medical education for the American Academy of Otolaryngic Allergy, the Allergy and Asthma Network, Medscape, National Jewish Health, NYC Health and Hospitals/One City Health, and the Pennsylvania Allergy and Asthma Association. Barry Make, MD has served on medical advisory boards for Aerocrine, AstraZeneca, BoehringerIngelheim, CSL Bering, GlaxoSmithKline, Forest, Novartis, Spiration, Theravance, and Sunovion. He has participated in research studies funded by AstraZeneca, BoehringerIngelheim, GlaxoSmithKline, Pfizer, Forest, Sunovion, and Pearl. Dr Make has conducted continuing medical education for American Thoracic Society, American College of Chest Physicians, Academy for Continued Healthcare Learning, Medscape, Projects in Knowledge, Catamount, Carden Jennings, Clevenad Clinic, Eastern Virginia Medical Center, Hybrid Communications, SPIRE, Foundation for Improving Patient Outcomes, Consensus, WebMD, National Jewish Health, and National Medical Association. He has received royalties from UpToDate. He has served on Data Monitoring Boards for Spiration and Baxalta. He has provided unbranded education talks for GlaxoSmithKline. Stephen Rennard, MD was employed by the University of Nebraska Medical Center during the conduct of this study and remains the Richard and Margaret Larson Professor of Pulmonary Research at UNMC and had a number of relationships with companies who provide products and/or services relevant to outpatient management of chronic obstructive pulmonary disease, including A2B Bio, Almirall, APT, AstraZeneca, Boehringer Ingelheim, Chiesi, CME Incite, CSL Behring, Dailchi Sankyo, Decision Resources, Dunn Group, Easton Associates, Forest, Gerson, GlaxoSmithKline, Johnson and Johnson, Medimmune, Novartis, Novis, Nycomed, Otsuka, Pearl, 
Pfizer, PriMed, Pulmatrix, Roche, Takeda, and Theravance; these relationships include serving as a consultant, advising regarding clinical trials, speaking at continuing medical education programs, and performing funded research both at basic and clinical levels. Dr Rennard is currently employed by AstraZeneca in which he owns shares. He does not own any stock in any other pharmaceutical companies. Byron Thomashow, MD has consulted for Boehringer-Ingelheim and has been on advisory boards for GlaxoSmithKline PLC, Novartis, AstraZeneca PLC, and Forest. Barbara P Yawn, MD, MSc has received research funding from NIH, AHRQ, CDC, and from BI for research on COPD. Dr Yawn has received compensation from Merck, Novartis, Astra Zeneca, and Forrest for COPD advisory boards on COPD, and Grifols for advisory board on Alpha-1 antitrypsin deficiency states. The authors report no other conflicts of interest in this work.

\section{References}

1. Martinez F, Mannino D, Leidy NK, et al. A new approach for identifying patients with undiagnosed chronic obstructive pulmonary disease. Am J Respir Crit Care Med. 2017;195(6):748-756.

2. Quezada W, Whippo B, Jellen P, et al. How well does CAPTURE translate? An exploratory analysis of a COPD case-finding method for Spanishspeaking patients. Chest. 2017;152(4):761-770.

3. Han MK, Kim MG, Mardon R, et al. Spirometry utilization for COPD: how do we measure up? Chest. 2007;132(2):403-409.

4. Han MK, Steenrod AW, Bacci ED, et al. Identifying patients with undiagnosed COPD in primary care settings: insight from screening tools and epidemiologic studies. Chronic Obstr Pulm Dis. 2015;2(2):103-121.

5. Hooper R, Burney P, Vollmer WM, et al. Risk factors for COPD spirometrically defined from the lower limit of normal in the BOLD project. Eur Respir J. 2012;39(6):1343-1353.

6. Qaseem A, Snow V, Shekelle P, et al. Diagnosis and management of stable chronic obstructive pulmonary disease: a clinical practice guideline from the American College of Physicians. Ann Intern Med. 2007; 147(9):633-638.

7. Rennard S, Thomashow B, Crapo J, et al. Introducing the COPD Foundation Guide for Diagnosis and Management of COPD, recommendations of the COPD Foundation. COPD. 2013;10(3):378-389.

8. Guirguis-Blake JM, Senger CA, Webber EM, Mularski RA, Whitlock EP. Screening for chronic obstructive pulmonary disease: evidence report and systematic review for the US preventive services task force. JAMA. 2016;315(13):1378-1393.
9. US. Preventive Services Task Force, Siu AL, Bibbins-Domingo K, et al. Screening for chronic obstructive pulmonary disease: US preventive services task force recommendation statement. JAMA. 2016;315(13): 1372-1377.

10. Jacome C, Marques A. Short- and long-term effects of pulmonary rehabilitation in patients with mild COPD: a comparison with patients with moderate to severe COPD. J Cardiopulm Rehabil Prev. 2016; 36(6):445-453.

11. O'Donnell DE, Gebke KB. Examining the role of activity, exercise, and pharmacology in mild COPD. Postgrad Med. 2014;126(5):135-145.

12. O'Donnell DE, Neder JA, Elbehairy AF. Physiological impairment in mild COPD. Respirology. 2016;21(2):211-223.

13. Rugbjerg M, Iepsen UW, Jorgensen KJ, Lange P. Effectiveness of pulmonary rehabilitation in COPD with mild symptoms: a systematic review with meta-analyses. Int J Chron Obstruct Pulmon Dis. 2015; 10:791-801

14. Welte T, Vogelmeier C, Papi A. COPD: early diagnosis and treatment to slow disease progression. Int J Clin Pract. 2015;69(3):336-349.

15. University of Michigan, United BioSource Corporation, NHBLI. Developing a COPD Case Finding Methodology for Primary Care (NCT01880177). ClinicalTrials.Gov First received: June 10, 2013/Last updated; 2016.

16. Bestall JC, Paul EA, Garrod R, Garnham R, Jones PW, Wedzicha JA. Usefulness of the Medical Research Council (MRC) dyspnoea scale as a measure of disability in patients with chronic obstructive pulmonary disease. Thorax. 1999;54(7):581-586.

17. Fletcher CM (Chairman). Standardised questionnaire on respiratory symptoms: a statement prepared and approved by the MRC Committee on the Aetiology of Chronic Bronchitis (MRC breathlessness score). BMJ. 1960;2:1665.

18. Jones PW, Harding G, Berry P, Wiklund I, Chen WH, Kline Leidy N. Development and first validation of the COPD Assessment Test. Eur Respir J. 2009;34(3):648-654.

19. Jones PW, Harding G, Wiklund I, et al. Tests of the responsiveness of the COPD assessment test following acute exacerbation and pulmonary rehabilitation. Chest. 2012;142(1):134-140.

20. GlaxoSmithKline. COPD Assessment Test (CAT) Healthcare Professional User Guide. 2012; Available from: http://www.catestonline. org/images/UserGuides/CATHCPUser\%20guideEn.pdf. Accessed April 12, 2017.

21. Global Initiative for Chronic Obstructive Lung Disease (GOLD). Global Strategy for the Diagnosis, Management, and Prevention of COPD. 2017. Available from: http://goldcopd.org/. Accessed April 2017.

22. Papaioannou M, Pitsiou G, Manika K, et al. COPD assessment test: a simple tool to evaluate disease severity and response to treatment. COPD. 2014;11(5):489-495. 


\section{Supplementary materials Sensitivity analyses: former smokers}

Given the difference in smoking status between the two groups, $\mathrm{SN}$ analyses were performed, testing the performance of the questionnaire, PEF, and CAPTURE (Questionnaire+PEF [350/250 and 450/350]) for differentiating COPD and no COPD in former smokers only $(n=56)$. Demographic and clinical characteristics of former smokers by group are shown in Tables S1 and S2. Results are presented in Table S3. $\mathrm{SN}, \mathrm{SP}$, and error were similar to values found in the entire sample (Table 3), suggesting that smoking history was not a confounding factor.

\section{Peak expiratory flow (PEF)}

Each subject performed three PEF maneuvers using a Vitalograph ${ }^{\circledR}$ AsmaPlan ${ }^{\circledR}$ mechanical PEF meter (Vitalograph $\mathrm{Ltd}, \mathrm{UK})$, with the highest value (L/min) used for analysis. Performance properties of PEF at varied thresholds in this sample stratified by sex are shown in Table S4.

\section{Clinical characteristics of patients whose COPD Assessment in Primary Care To Identify Undiagnosed Respiratory Disease and Exacerbation Risk (CAPTURE ${ }^{\mathrm{TM}}$ ) suggests that further diagnostic evaluation is advised}

CAPTURE was developed to identify patients in need of diagnostic evaluation for undiagnosed COPD and a forced expiratory volume in 1 second $\left(\mathrm{FEV}_{1}\right)<60 \%$ or exacerbation risk. This study assessed the sensitivity ( $\mathrm{SN})$, specificity (SP), and error of this case-finding method for identifying patients with an $\mathrm{FEV}_{1} \geq 60 \%$ predicted.

To assess whether the evaluation process was identifying symptomatic patients, dyspnea (modified Medical Research Council $[\mathrm{mMRC}]>2$ ), or health status impairment (COPD Assessment Test $\left[\mathrm{CAT}^{\mathrm{TM}}\right]>10$ ) was examined. Table $\mathrm{S} 5$ shows the results of these analyses for the 350/250 and 450/350 PEF thresholds. In both cases, most of the patients who would be referred for further diagnostic evaluation reported impaired health status and a substantial portion reported dyspnea. Although more patients are referred for further testing when the higher PEF threshold (450/350) is used, those referred are more likely to report impaired health status or high levels of dyspnea compared to those whose scores suggested that no further testing was warranted. These results suggest that CAPTURE (PEF 450/350) may be useful for identifying cases of COPD with an $\mathrm{FEV}_{1}>60 \%$ predicted, many of whom meet GOLD guidelines for "more symptomatic" disease.

Table SI Demographic characteristics of former smokers $(\mathrm{N}=76)$ by group

\begin{tabular}{|c|c|c|c|}
\hline \multirow[t]{2}{*}{ Characteristic } & \multicolumn{2}{|c|}{ Former smokers $(\mathrm{N}=76)$} & \multirow[t]{2}{*}{$p$-value } \\
\hline & $\operatorname{COPD}^{\mathrm{b}}(\mathrm{n}=48)$ & No $\operatorname{COPD}^{c}(\mathbf{n}=\mathbf{2 8})$ & \\
\hline \multicolumn{4}{|l|}{ Age (years) } \\
\hline Mean (SD) & $67.4(7.9)$ & $62.0(11.1)$ & 0.0284 \\
\hline Range & $5 I-85$ & $40-88$ & \\
\hline Sex, n (\%) male & $24(50)$ & $10(36)$ & 0.2270 \\
\hline \multicolumn{4}{|l|}{ Ethnic background, n (\%) } \\
\hline Not Hispanic or Latino & $46(98)$ & $28(100)$ & 1.000 \\
\hline \multicolumn{4}{|l|}{ Racial background, n (\%) } \\
\hline White & $44(92)$ & $25(89)$ & \\
\hline Non-white & $4(8)$ & $3(I I)$ & 0.7039 \\
\hline \multicolumn{4}{|l|}{ Employment, n (\%) } \\
\hline Employed (full- or part-time) & $10(21)$ & $10(21)$ & 0.0052 \\
\hline Not employed/others ${ }^{e}$ & $38(79)$ & $38(79)$ & \\
\hline \multicolumn{4}{|l|}{ Education status, n (\%) } \\
\hline High school or less & $22(46)$ & $22(46)$ & 0.0934 \\
\hline Some college, vocational training & $9(19)$ & $9(19)$ & \\
\hline College degree or more & $17(35)$ & $17(35)$ & \\
\hline
\end{tabular}

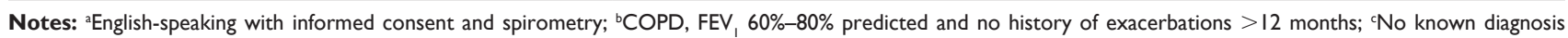
or treatment for COPD and $\mathrm{FEV}_{\mathrm{I}} / \mathrm{FVC} \geq 0.70$; `Subject self-identified; non-white: American Indian or Alaskan Native (I, I), Asian (0, I), Black or African American (I, 2), others $(\mathrm{I}, 0) .{ }^{\mathrm{e} O}$ thers: homemaker, unemployed, and not specified.

Abbreviations: $\mathrm{FEV}_{1}$, forced expiratory volume in I second; FVC, forced vital capacity. 
Table S2 Clinical characteristics of former smokers $(\mathrm{N}=76)$ by group

\begin{tabular}{|c|c|c|c|}
\hline Characteristic & $\operatorname{COPD}^{\mathrm{b}}(\mathrm{n}=48)$ & No $\operatorname{COPD}^{\mathrm{c}}(\mathrm{n}=\mathbf{2 8})$ & $p$-value \\
\hline \multicolumn{4}{|l|}{ Spirometry, mean (SD) } \\
\hline $\mathrm{FEV}_{1}$, median & 1.9 & 2.4 & 0.0023 \\
\hline Mean (SD) & $2.0(0.6)$ & $2.5(0.7)$ & \\
\hline $\mathrm{FEV}_{1} \%$ predicted, median & 68.0 & 85.0 & 0.0020 \\
\hline Mean (SD) & $73.5(13.2)$ & $85.0(17.3)$ & \\
\hline $\mathrm{FEV}_{1} / \mathrm{FVC}$ & $0.60(0.06)$ & $0.78(0.06)$ & $<0.0001$ \\
\hline Peak flow (PEF) & $320.9(114.7)$ & $396.3(85.0)$ & 0.0035 \\
\hline \multicolumn{4}{|l|}{ mMRC (0-4 scale) } \\
\hline Median & 1 & 0 & $<0.0001$ \\
\hline Mode (n, \%) & I $(24,5$ I) & $0(25,89)$ & \\
\hline $\mathrm{mMRC}>2, \mathrm{n}(\%)$ & $12(26)$ & I (4) & 0.0243 \\
\hline \multicolumn{4}{|l|}{ САТТ Тм } \\
\hline Median & 15.0 & 5.0 & $<0.0001$ \\
\hline Mean (SD) & $14.5(6.6)$ & $5.5(4.7)$ & \\
\hline CAT $>10, n(\%)$ & $38(79)$ & $5(18)$ & $<0.000$ I \\
\hline $\mathrm{mMRC}>2$ and CAT $>10, \mathrm{n}(\%)$ & $12(26)$ & I (4) & 0.0243 \\
\hline mMRC $>2$ or $C A T>10, n(\%)$ & $38(79)$ & $5(18)$ & $<0.0001$ \\
\hline Comorbid conditions (any), $\mathrm{n}(\%)$, yes & $48(100)$ & $25(89)$ & 0.0466 \\
\hline \multicolumn{4}{|l|}{ Self-report activity on most days, $n(\%)$} \\
\hline Sit, lie down, walk around home & $26(54)$ & $10(36)$ & 0.1202 \\
\hline Very active or exercise & $22(46)$ & $18(64)$ & \\
\hline
\end{tabular}

Notes: ${ }^{a}$ English-speaking subjects with informed consent and spirometry; ${ }^{b} \mathrm{COPD}, \mathrm{FEV}, 60 \%-80 \%$ predicted and no history of exacerbations $>12$ months; ${ }^{\mathrm{c} n o}$ known diagnosis or treatment for COPD and $F E V_{1} / F V C \geq 0.70$.

Abbreviations: CAT, COPD Assessment Test; FEV , forced expiratory volume in I second; FVC, forced vital capacity; GOLD, Global Initiative for Chronic Obstructive Lung Disease; mMRC, modified Medical Research Council dyspnea scale.

Table S3 Performance of the questionnaire, PEF, and CAPTURE for differentiating COPD ${ }^{a}(n=48)$ from No COPD ${ }^{b}(n=28)$ in former smokers $(\mathrm{N}=76)$

\begin{tabular}{|c|c|c|c|c|c|}
\hline \multirow[t]{2}{*}{ Property } & \multirow{2}{*}{$\frac{\text { Questionnaire }}{\text { Score }>2}$} & \multicolumn{2}{|l|}{ PEF $^{\mathrm{c}}$} & \multicolumn{2}{|c|}{ CAPTURE $^{c}$ (Questionnaire+PEF) } \\
\hline & & $350 / 250$ threshold & $450 / 350$ threshold & $350 / 250$ threshold & $450 / 350$ threshold \\
\hline Sensitivity (\%) & 87.5 & 33.3 & 81.3 & 39.6 & 70.8 \\
\hline Specificity (\%) & 67.9 & 92.9 & 57.1 & 96.4 & 85.7 \\
\hline Error (\%) & 19.7 & 44.7 & 27.6 & 39.5 & 23.7 \\
\hline
\end{tabular}

Notes: ${ }^{\mathrm{a} C O P D}, \mathrm{FEV}, 60 \%-80 \%$ predicted, and no history of exacerbations $>12$ months; ${ }^{\mathrm{b}}$ no known diagnosis or treatment for COPD and $\mathrm{FEV} / \mathrm{FVC} \geq 0.70$. ${ }^{\mathrm{c}} \mathrm{PEF}$ rate (L/min), thresholds: males/females.

Abbreviations: $\mathrm{FEV}_{1}$, forced expiratory volume in I second; FVC, forced vital capacity; PEF, peak expiratory flow. 
Table S4 Performance properties of PEF thresholds for differentiating milder cases of COPDa from patients without COPD by sex

\begin{tabular}{|c|c|c|c|c|c|c|c|c|}
\hline \multicolumn{9}{|l|}{ Males $(n=66)$} \\
\hline \multirow[t]{2}{*}{ Property } & \multicolumn{8}{|c|}{ PEF threshold $(\mathrm{L} / \mathrm{min})^{c}$} \\
\hline & 350 & 375 & 400 & & 425 & $450^{d}$ & 475 & 500 \\
\hline Sensitivity (\%) & 37.5 & 52.5 & 65.0 & & 80.0 & 80.0 & 82.5 & 85.0 \\
\hline Specificity (\%) & 88.5 & 88.5 & 80.8 & & 69.2 & 65.4 & 53.8 & 50.0 \\
\hline Error (\%) & 42.4 & 33.3 & 28.8 & & 24.2 & 25.8 & 28.8 & 28.8 \\
\hline \multicolumn{9}{|c|}{ Females $(n=94)$} \\
\hline \multirow[t]{2}{*}{ Property } & \multicolumn{8}{|c|}{ PEF ${ }^{c}$ threshold (L/min) } \\
\hline & 250 & 275 & & 300 & & 325 & $350^{d}$ & 375 \\
\hline Sensitivity (\%) & 39.4 & 66.7 & & 69.7 & & 75.8 & 87.9 & 93.9 \\
\hline Specificity (\%) & 91.8 & 86.9 & & 85.2 & & 80.3 & 67.2 & 42.6 \\
\hline Error (\%) & 26.6 & 20.2 & & 20.2 & & 21.3 & 25.5 & 39.4 \\
\hline
\end{tabular}

Notes: ${ }^{a}$ COPD, FEV $60 \%-80 \%$ predicted and no history of exacerbations $>12$ months. ${ }^{b}$ No known diagnosis or treatment for COPD and FEV $/$ FVC $\geq 0.70$. $\mathrm{PEFF}$ rate, L/min. ¿Selected threshold.

Abbreviations: $\mathrm{FEV}_{1}$, forced expiratory volume in I second; FVC, forced vital capacity; PEF, peak expiratory flow.

Table S5 Prevalence of dyspnea and health status by CAPTURE ${ }^{\mathrm{TM}}$ Response ${ }^{\mathrm{a}}$ in patients with $\mathrm{COPD}^{\mathrm{b}}(\mathrm{N}=73)$

\begin{tabular}{|c|c|c|c|c|c|c|}
\hline \multirow[t]{3}{*}{ Characteristic } & \multicolumn{3}{|c|}{ CAPTURE (PEF 350/250)c } & \multicolumn{3}{|c|}{ CAPTURE (PEF 450/350) ${ }^{\mathrm{d}}$} \\
\hline & \multicolumn{3}{|c|}{ Diagnostic testing recommended } & \multicolumn{3}{|c|}{ Diagnostic testing recommended } \\
\hline & Yes, $n=29$ (40\%) & No, $n=44(60 \%)$ & p-levele & Yes, $n=52(70 \%)$ & No, $n=21(30 \%)$ & p-level \\
\hline $\mathrm{mMRC}>2, \mathrm{n}(\%)$ & $12(43)$ & $8(18)$ & 0.0227 & $19(37)$ & I (5) & 0.0042 \\
\hline $\mathrm{CAT}^{\mathrm{TM}}>10, \mathrm{n}(\%)$ & $26(90)$ & $31(70)$ & 0.0817 & $45(86)$ & $12(57)$ & 0.0060 \\
\hline mMRC $>2$ and CAT $>10, n(\%)$ & $12(43)$ & $8(18)$ & 0.0227 & $19(37)$ & I (5) & 0.0042 \\
\hline
\end{tabular}

Notes: auestionnaire+PEF results suggest that further diagnostic evaluation is warranted (yes/no). ${ }^{b} \mathrm{COPD}$, FEV $60 \%-80 \%$ predicted, and no history of

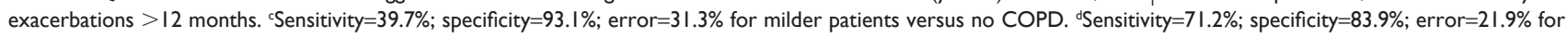
milder patients versus no COPD. ${ }^{e}$ Chi-square $\left(\chi^{2}\right)$ or Fisher's exact $($ cell $\mathrm{n}<5$ ).

Abbreviations: CAT, COPD Assessment Test; FEV , forced expiratory volume in I second; mMRC, modified Medical Research Council dyspnea scale; PEF, peak expiratory flow.

\section{Publish your work in this journal}

The International Journal of COPD is an international, peer-reviewed journal of therapeutics and pharmacology focusing on concise rapid reporting of clinical studies and reviews in COPD. Special focus is given to the pathophysiological processes underlying the disease, intervention programs, patient focused education, and self management protocols.

\section{Dovepress}

This journal is indexed on PubMed Central, MedLine and CAS. The manuscript management system is completely online and includes a very quick and fair peer-review system, which is all easy to use. Visit $\mathrm{http}: / /$ www.dovepress.com/testimonials.php to read real quotes from published authors. 